(C2016, Elsevier. Licensed under the Creative Commons Attribution-NonCommercialNoDerivatives 4.0 International http://creativecommons.org/about/downloads

cc) $(1)$ 


\title{
Talking about Durables
}

\begin{abstract}
Using a survey of 349 respondents, we investigate the triggers of word of mouth (WOM) in four durables categories and compare this evidence with previous findings for services. For these durables, positive word of mouth (PWOM) is mostly triggered by advertising and customer satisfaction with the product, while negative word of mouth (NWOM) is rare and mostly triggered by the content of conversation and the perception that other persons need advice. This contrasts with previously established findings for services where advertising has little effect on PWOM and dissatisfaction has substantial effect on NWOM. These differences have important implications: they suggest that durable ads should be tested to check that they trigger PWOM and that service providers should pay more attention to the satisfaction derived from the service experience.
\end{abstract}

\section{Introduction}

Word of mouth (WOM) can have a potent effect on sales; the Keller Fay Agency (2014) reports that one in eight recommendations results in a sale. For this reason, we should research the triggers of WOM and pay particular attention to those triggers that can be influenced. Bayus (1985), and Graham and Havlena (2007), have shown that one trigger is advertising and Keller and Fay (2012) report that this stimulates about 25 percent of WOM. Despite this evidence, ad testing is not normally conducted to evaluate the carryover of ad exposure into WOM so that ads that are particularly effective at inducing WOM are not identified. Managers would have more confidence in their ad spending if they found that it produced a substantial carryover into PWOM and had little impact on NWOM.

A second trigger of WOM is satisfaction (for PWOM) and dissatisfaction (for NWOM), as found by East et al. (2015) for services; here, managers can affect the level of WOM by controlling product quality. If PWOM/NWOM is found to be more dependent on satisfaction/dissatisfaction than advertising, managerial effort might be better directed to raising product quality.

Thus the allocation of resources to advertising and product development should take account of how much advertising and satisfaction/dissatisfaction induce WOM. Evidence on such matters does not compel a specific marketing strategy but an absence of such evidence means that managerial judgment is poorly informed.

A further reason for understanding what triggers WOM is the need to understand the process of diffusion of innovation. There is general agreement that new products and ideas become adopted in a two-stage process: the mass media persuade some persons to adopt and these people then persuade others to follow them. This idea was first expressed by Tarde (1890) and independently developed by Lazarsfeld, Berelson and Gaudet (1944) and Katz (1957), while Bass (1969) presented a model of this process which was fitted to data on durables. Understanding the diffusion process is likely to be assisted by evidence on how much advertising triggers PWOM in different categories and category groupings.

We approach this matter by using an established typology of factors that induce PWOM and NWOM and investigate four durable categories. In this way, we show the proportions of WOM attributed to advertising, satisfaction and other factors.

\section{Triggers of Word of Mouth}

The antecedents of WOM may be psychological variables such as motivations and attitudes (e.g. Dichter 1966, Sundarum, Mitra and Webster 1998), features of the product such as quality and reliability (e.g. Anderson 1998, Feng and Zhang 2010), or contextual factors such as the content of conversation and whether the communicator thinks that advice 
is needed by the receiver. Mangold, Miller and Brockway (1999) developed a typology covering the motivational and contextual factors that stimulated WOM about services; these stimuli included advertising, satisfaction/dissatisfaction with the product, perceived need for advice, conversational content, and joint decision making. East et al. (2015) used this typology to gather data on the relative frequencies of WOM stimuli across four service categories; here, we use the typology to establish the frequencies of the WOM stimuli across four durable categories.

\subsection{Comparisons between categories}

East et al. (2015) compared the triggers of WOM about restaurants, mobile airtime provision, financial services, and holiday destinations and found little difference between categories in the frequencies of the triggers. The main stimuli were satisfaction in the case of PWOM, dissatisfaction in the case of NWOM and conversation (PWOM and NWOM). Advertising was responsible for only seven percent of both PWOM and NWOM. We have been unable to find recent research relating to the sources of WOM about durables though Day and Ash (1979) noted wide differences in satisfaction in this domain so this might be one basis for differences between categories. The triggers of WOM on durables might also reflect variation in ad budgets but we cannot point to research on which a prediction could be based. We therefore seek to establish facts on this matter with the first research question:

$R Q$ 1: How do the frequencies of factors stimulating WOM differ across durable categories?

\subsection{Comparisons between durables and services}

The precision manufacture of modern durables has ensured that product failures are now very rare. When faults occur in production, the product can often be withdrawn before sale, thus avoiding dissatisfaction. By contrast, service deficiencies emerge at the point of delivery where they cannot be rectified. The functions of durables can be precisely specified so that buyers have a clear idea of the benefits of purchase and this again contrasts with services where there may be uncertainty about outcomes. These comparisons suggest that more risk applies to services than durables and that service use may create more consumer dissatisfaction as found by Murray and Schlacter (1990).

One other factor that could produce a difference between durables and services is the effectiveness of advertising when the product is tangible. Benefits from such a product may be easier to communicate and this could raise the impact of ads on durables; if so, we might expect more ad-induced WOM about durables. The research question is:

$R Q 2$. How do the frequencies of factors stimulating WOM differ between durables and services?

\subsection{Comparisons between PWOM and NWOM}

In their study of services, East et al. (2015) found that the factor frequencies stimulating PWOM were closely similar to those stimulating NWOM (when satisfaction is used for PWOM and dissatisfaction for NWOM). This does not seem likely to apply to durables. If advertising has more effect in stimulating WOM about durables, this will impact mainly on PWOM since advertising is not designed to elicit NWOM. Dissatisfaction may have less of a role in triggering NWOM about durables, compared with services. A review by Peterson and Wilson (1992), using data based on a range of goods and services, indicates that satisfaction is much more common than dissatisfaction with a ratio in the region of 10:1 but from the foregoing discussion it seems likely that this ratio will be smaller for services and larger for durables so there will be less dissatisfaction to trigger NWOM in the case of durables. The research question is: 
RQ3: How do the frequencies of factors stimulating PWOM and NWOM about durables differ? More specifically, does satisfaction stimulate more PWOM than dissatisfaction stimulates NWOM?

\section{Study}

\subsection{Questionnaire items and survey}

As in the earlier work by East et al. (2015), we presented nine factors from the typology of Mangold, Miller and Brockway (1999) as a questionnaire item in a survey. As in the original work by Mangold et al. (1999), the present study was restricted to WOM that had been received, rather than given, by the respondent. (Thus, it is the triggers as assessed by the receiver that we measure).

The four durables were cars, vacuum cleaners, mobile phones and computers. These were chosen because of their wide ownership and because of their different characteristics. In the East et al. study, quite different services were chosen and we followed this approach so that, if similarities were found between durables, this pattern could not be ascribed to a narrow choice of products. Table 1 shows the factors and main question form with the response format, taking cars as the example category. Each item of this form was followed by a question which established whether the advice had been received in the last six months. After the question pair dealing with positive advice on cars, a further pair of questions dealt with negative advice on cars. Then the questioning moved to the next category (vacuum cleaners).

Table 1. Items used in the questionnaire (car example)

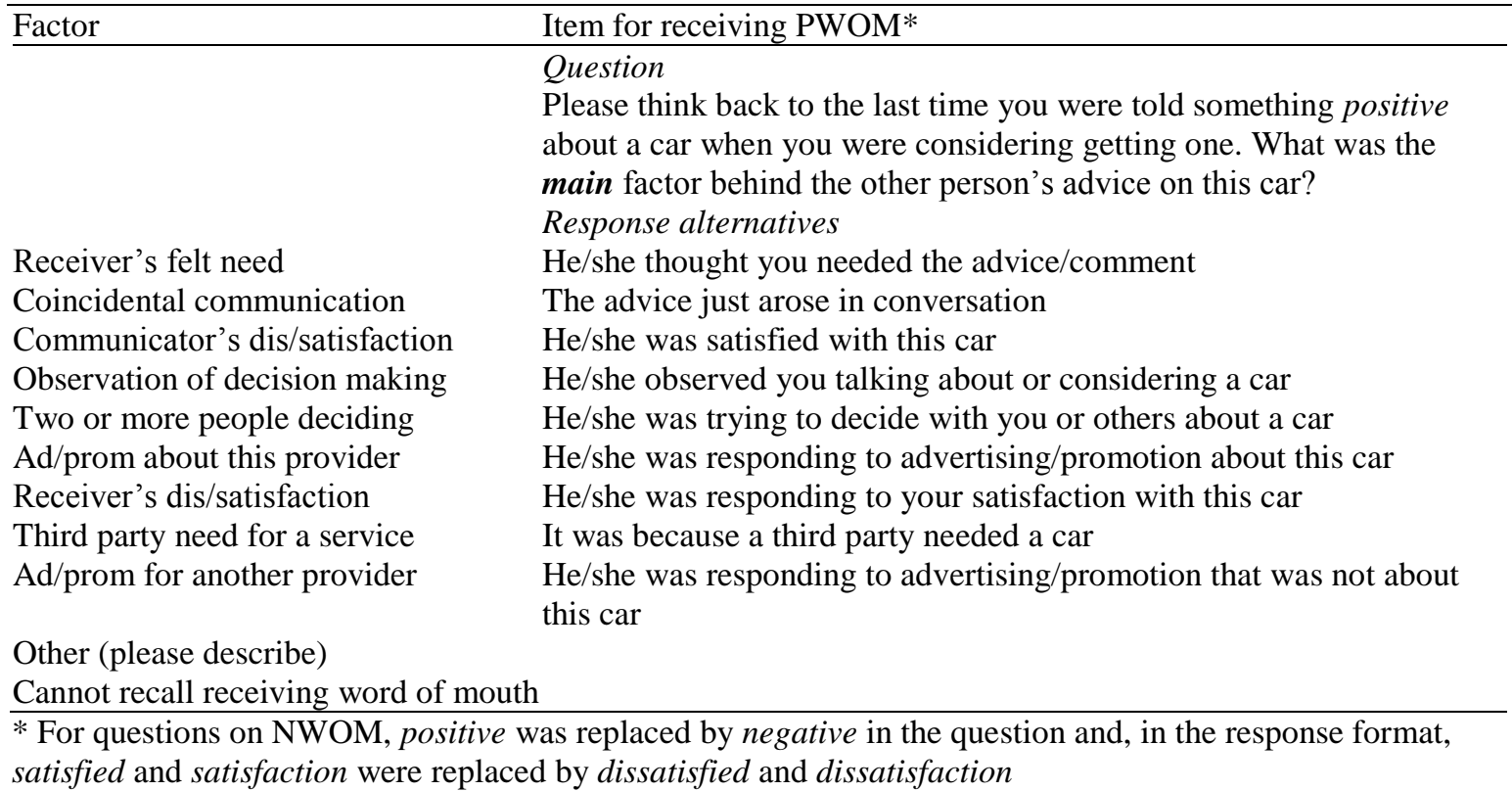

Data from a convenience sample of 349 respondents were gathered in the summer of 2014. The questionnaires were distributed to homes and to people in public spaces such as parks and coffee bars. Nearly all those respondents who agreed to help provided a completed questionnaire. No reward was used. To check on presentation order effects, two versions of the questionnaire were produced. Version A used the items in the order shown in Table 1 while version B reversed the order of the first nine items. The two versions were alternated in the packs given to fieldworkers and this produced 174 returns of version A and 175 responses for version $B$. The sample was $48 \%$ female and the median age was 36 . 


\section{Checks}

\subsection{Presentation order effect}

To check on any bias produced by the order of presentation, we computed a Total WOM measure by summing the means of factor frequencies for PWOM and NWOM on the four categories. If there is a tendency for earlier items to be checked more often, this will show up in the correlation of the frequencies found for Versions A and B of the questionnaire (after the Version $\mathrm{B}$ data has been put into the Version A order). The correlation between the frequencies of the first nine items of A and B was 0.96 ( $p<.001)$, which rules out any substantial presentation order effect. Note that "other" and "cannot recall receiving word of mouth" were always at the end of the response list.

\subsection{Age and gender}

Demographic differences were checked to see whether the factor frequencies were related to these measures. We compared the Total WOM of those aged less than 36 (49\%) with the rest because this gave the most even split of the sample. The correlation between the frequencies for the younger and older segments was $0.96(\mathrm{p}<0.001)$. Thus, there is little agebased difference in responses. Using Total WOM again, a correlation of 0.98 was found between the factor frequencies of men and women, so there is no appreciable gender difference.

\section{3. "Other" and "Cannot recall" responses}

The "Other" response was mostly used by respondents to state that they had not bought the durable. "Other" and "Cannot recall receiving word of mouth" were much more common for NWOM with the result that there were only 246 cases for analysis across the four categories compared with 1106 for PWOM. In the main analysis below, the "Other" and "Cannot recall" responses were excluded.

\subsection{Common method bias}

When a question form is repeated for different categories in a questionnaire, as in this work, there is a danger that later responses will automatically follow the pattern of earlier responses. This type of response simplification can be reduced by designing questions appropriately (MacKenzie and Podsakoff, 2012). Our questions were short, the alternative responses were provided, the matter was familiar, and was neither complex nor abstract. However the questions had to have common scale attributes, which might have produced some automatic response.

Statistical remedies for common method bias are discussed by Podsakoff, MacKenzie and Podsakoff (2012). We used a version of what is described as the marker variable technique. The most common response was selected and those who checked this for category A were examined to see how frequently they checked the same response for categories B, C, and D. For PWOM, the most common response was "ad/prom about the product" which was checked by $44 \%$. On average, of those who selected this response for category A, 39\% selected it for other categories. Since common method bias would tend to raise the frequency above $44 \%$, our test showed no sign of common method bias. This test was not conducted on NWOM because the number of respondents selecting the most common response was too low.

\section{Findings}

5.1. Recall percentages 
The first numeric row of Table 2 shows the percentages of respondents who were nonbuyers or those who could not recall receiving WOM on the category. This is followed by the number of respondents left for analysis and the percentages are based on this number.

\subsection{RQ 1: How do the frequencies of factors stimulating WOM differ across durable categories?}

The data in Table 2 are arranged in descending order of the average frequencies of the factors found for PWOM. The individual category data in Table 2 show that, in the case of PWOM, the effects of advertising and communicator dis/satisfaction differ substantially across categories. PWOM about vacuum cleaners is particularly related to the communicator's satisfaction while PWOM on mobile phones is strongly related to advertising. The computer category is exceptional because PWOM relates most to third party need. Table 3 shows the correlations between factor percentage columns for PWOM. These are all positive but range widely. A Cronbach alpha test across the four categories exceeds the 0.7 criterion at 0.73 for PWOM. In the case of NWOM, the pattern is more uniform and emphasizes third party need, coincidental communication, and the receiver's need (though vacuum cleaners, with few cases, show a zero score for the receiver's need). Table 4 shows the correlations between factor percentage columns for NWOM and, like PWOM, these are all positive but range widely. The Cronbach alpha score across the four categories is 0.83 for NWOM. Given the alpha scores and the need for clarity, we use the mean columns in Table 5 for the comparisons that follow.

Table 2. Factor Percentages by Category for PWOM and NWOM

\begin{tabular}{|c|c|c|c|c|c|c|c|c|c|c|}
\hline \multirow{5}{*}{$\begin{array}{l}\text { No recall/other } \% \\
\text { Leaving } \mathrm{N}=\end{array}$} & \multicolumn{5}{|c|}{ PWOM } & \multicolumn{5}{|c|}{ NWOM } \\
\hline & Car & Vac. Cl & Mob. Ph & Comp. & Mean & Car & Vac. $\mathrm{Cl}$ & Mob. Ph & Comp. & Mean \\
\hline & 14 & 37 & 6 & 23 & 20 & 72 & 93 & 87 & 77 & 82 \\
\hline & 298 & 217 & 329 & 262 & 1106 & 96 & 23 & 47 & 80 & 246 \\
\hline & $\%$ & $\%$ & $\%$ & $\%$ & $\%$ & $\%$ & $\%$ & $\%$ & $\%$ & $\%$ \\
\hline Ad/prom about this product & 47 & 9 & 75 & 31 & 41 & 1 & 4 & 13 & 1 & 5 \\
\hline Communicator's dis/satis. & 19 & 74 & 11 & 20 & 31 & 2 & 0 & 4 & 4 & 3 \\
\hline Third party need & 10 & 8 & 2 & 34 & 14 & 22 & 30 & 9 & 58 & 30 \\
\hline Coincidental communication & 7 & 5 & 4 & 7 & 6 & 37 & 44 & 32 & 15 & 30 \\
\hline Receiver's felt need & 7 & 0 & 3 & 5 & 4 & 22 & 0 & 17 & 11 & 13 \\
\hline Observation of dec. making & 4 & 1 & 2 & 2 & 2 & 6 & 4 & 6 & 0 & 4 \\
\hline Two or more people deciding & 2 & 2 & 1 & 2 & 2 & 4 & 9 & 6 & 0 & 5 \\
\hline Receiver's dis/satisfaction & 2 & 2 & 1 & 1 & 2 & 3 & 4 & 4 & 6 & 4 \\
\hline $\mathrm{Ad} /$ prom for another product & 2 & 1 & 2 & 0 & 1 & 3 & 4 & 9 & 1 & 4 \\
\hline
\end{tabular}

Table 3. PWOM: Correlations of factor percentage columns across categories

\begin{tabular}{|l|l|l|l|l|l|}
\hline & Vacuum Cleaner & & Mobile Phone & Computer \\
\hline Car & .30 & & $.96^{* *}$ & $.72^{*}$ \\
\hline Vacuum Cleaner & & & .09 & .36 \\
\hline Mobile Phone & & & & .59 \\
\hline
\end{tabular}

$*<0.05, * *<0.001$

Table 4. NWOM: Correlations of factor percentage columns across categories

\begin{tabular}{|l|l|l|l|}
\hline & Vacuum Cleaner & Mobile Phone & Computer \\
\hline Car & $.81^{* *}$ & $.84^{* *}$ & .55 \\
\hline Vacuum Cleaner & & $.69^{*}$ & .60 \\
\hline Mobile Phone & & & .14 \\
\hline
\end{tabular}

$*<0.05, * *<0.001$ 
5.3. RQ2: How do the frequencies of factors stimulating WOM about durables and services differ?

The mean factor scores obtained in this study are compared with those found by East et al. (2015) for services, as shown in Table 5. The correlations between the factor percentage columns for services and durables are close to zero (PWOM, $r=0.13, p=0.73$; NWOM, $r=$ $0.01, \mathrm{p}=0.98$ ). The only strong commonalities were that satisfaction is a major factor stimulating PWOM for both durables and services and coincidental communication was important for triggering NWOM about both services and durables. Otherwise, the findings show that advertising was a major stimulus for PWOM about durables but not about services (test of proportions, $\mathrm{p}<0.0001$ ) and that dissatisfaction was a major stimulus for NWOM about services but not about durables $(\mathrm{p}<0.0001)$. Thus services and durables show significant differences with regard to the factors inducing WOM.

Table 5. Percentages attributed to different factors for durables and for services (services from East et al. (2015)

\begin{tabular}{lrrrr}
\hline & \multicolumn{2}{c}{ Durables } & \multicolumn{2}{c}{ Services } \\
\hline & PWOM & NWOM & PWOM & NWOM \\
Ad/prom about this provider & 41 & 5 & 5 & 4 \\
Communicator's dis/satisfaction & 31 & 3 & 27 & 26 \\
Third party need & 14 & 30 & 5 & 6 \\
Coincidental communication & 6 & 30 & 19 & 19 \\
Receiver's felt need & 4 & 13 & 7 & 7 \\
Observation of decision making & 2 & 4 & 11 & 11 \\
Two or more deciding & 2 & 5 & 9 & 11 \\
Receiver's dis/satisfaction & 2 & 4 & 13 & 11 \\
Ad/promo for another provider & 1 & 4 & 2 & 3 \\
\hline
\end{tabular}

5.4. RQ3: How do the frequencies of factors stimulating PWOM and NWOM about durables differ? More specifically, does satisfaction stimulate more PWOM than dissatisfaction stimulates NWOM?

Inspecting the data for durables in Table 5, advertising/promotion is a common trigger of PWOM on durables but is rare as a trigger of NWOM (test of proportions, $p=0.0001$ ). Communicator satisfaction is a major trigger of PWOM but dissatisfaction is rare as a trigger of NWOM $(\mathrm{p}<0.0001)$; this answers the subsidiary question in the heading. NWOM on durables appears to be based more on coincidental conversation and the perceived needs of others compared with PWOM ( $\mathrm{p}=0.0007)$. When the mean frequencies of factors stimulating PWOM and NWOM about durables are correlated there is no significant relationship $(\mathrm{r}=-.15, \mathrm{p}=.69)$. When this test is repeated for each category separately the associations are again trivial, except for computers where the correlation approaches significance $(\mathrm{r}=0.58, \mathrm{p}=0.1)$.

\section{Discussion}

\subsection{The need for facts}

Marketing researchers need factual evidence to locate problems and to give context to findings. Usually, relevant facts can be obtained from market research and trade statistics but, in this case, there was no available evidence and we conducted the research ourselves. The evidence shows that advertising produces a substantial PWOM carryover, which suggests some gaps in our understanding of how products should be supported and in the practice of ad testing, which we discuss below.

\subsection{Application: PWOM depends on factors that can be influenced}


We show that advertising triggers 42 per cent of the PWOM on the four durables studied. This supports Givon and Horsky's (1990) suggestion that PWOM is the vehicle for much of the effect of durable advertising and illustrates the widely accepted view that the mass media stimulate social influence and thus bring about the diffusion of innovation (e.g. Katz 1957, Bass 1969). Second to advertising, PWOM is triggered by satisfaction with the product in the case of durables. After this, a perceived need for information seemed particularly important as a trigger to PWOM in the case of computers. This evidence shows that PWOM about durables should be an important managerial concern because it is mostly triggered by advertising and satisfaction, which can be influenced by appropriate content in marketing communications and by managing product quality.

NWOM about durables mostly arises in conversations and in response to the needs of others, and these circumstances may also be affected indirectly by product quality and advertising. Thus, although managers cannot directly control WOM, they can adapt product form and publicity so that PWOM is promoted and NWOM is deterred. To do this, managers need research on their specific category because, despite the Cronbach alpha scores obtained, our evidence shows substantial variation in the triggers of WOM across categories. Managers also need research on suitable content for advertising and the specific features of products that are satisfying. When advice occurs because potential customers are seen to lack information, research is required to establish what is needed so that publicity can incorporate this information.

We stress that our evidence points the way but is insufficient on its own. For example, it is not clear whether ads have less impact on PWOM about vacuum cleaners compared with other durables because the ad spending is low in this category, the copy poor, or because satisfaction with the product crowds out the effect of advertising. Thus, further research is needed to clarify the contribution of these factors in any category.

\subsection{Durables and services}

Our evidence on durables differs sharply from findings on services supplied by East et al. (2015) who, unlike findings in the present study, found uniformity in the trigger frequencies across categories and between PWOM and NWOM. Furthermore, the factors that stimulated WOM about durables differed from those that stimulated WOM about services, particularly with respect to advertising. Why does durable advertising induce PWOM when this effect is largely absent for services? We can speculate that this difference relates to the weight of advertising used in different domains and to the effectiveness of ads on tangible products where product functions and benefits can be specified more exactly. We also found a difference between the sectors in the effect of dissatisfaction; the evidence suggests that service providers should be more concerned about avoiding dissatisfaction than durable manufacturers. This was a conclusion reached by Anderson, Fornell and Rust (1997) in modelling that took account of the degree of customization and standardization that was possible in services and durables.

\subsection{Ad testing}

Our evidence that advertising is the main basis for PWOM about durables suggests that ad copy should be tested for its effect on PWOM because this carryover may add substantially to the sales effect of the advertising. Ad testing has used recall, persuasion, physiological responses such as eye-tracking and measures of actual sales response in test communities such as the BehaviorScan split-cable method developed by Information Resources Incorporated (IRI) as reported by Hu, Lodish, and Krieger (2007); however, it is not known how much an ad that is, say, better recalled is also more likely to be used in WOM. If there is little association, the effectiveness of the ad may be poorly measured by recall. This is a 
problem that affects all short-term methods of ad testing. Split-cable tests allow time for WOM to propagate so that the effect of WOM may be included in the test but, when tests are conducted in one community as is the case for IRI's BehaviorScan, the WOM may pass between respondents in the test and control conditions so that the experimental design is compromised. These problems may not matter too much in the grocery field if it is found that there is little ad-induced PWOM in this domain, but a new approach is required for durables that assesses transmissible content because ads clearly trigger a substantial amount of PWOM. We suggest that one method is to ask respondents to give product advice after hearing ads; the advice can be scored to see how many elements of the ad are incorporated.

\subsection{The relative volume of PWOM and NWOM on durables}

Average ratios of PWOM to NWOM tend to be in the region of 3 to 1 (e.g. East. Hammond and Wright 2007). Our evidence indicates a higher ratio of 4.5 to 1 for durables if the frequency of receiving PWOM is the same as that for receiving NWOM. However, frequencies tend to fall as penetration falls (Ehrenberg 1988) and, taking account of this, the ratio of PWOM to NWOM will be substantially greater than 4.5 to 1 . We suggest that this relatively high ratio occurs because there is little dissatisfaction with modern durables and because ad copy has a strong effect on PWOM but little effect on NWOM in this domain. A practical implication of this finding is that durable manufacturers should be less concerned about reducing NWOM than raising PWOM because there is less NWOM to do damage. Related to this, both East et al. (2008) and Sweeney et al. (2014) found that NWOM had somewhat less impact than PWOM on purchase intention.

\section{Conclusion}

The factors that trigger WOM about durables are substantially different from those that trigger WOM about services. For durables, 42 per cent of all PWOM is triggered by advertising, compared with 7 per cent in the case of services and, whereas 37 per cent of NWOM about services is triggered by the receiver's or giver's dissatisfaction, only 7 per cent of NWOM about durables is produced in this way. The factors responsible for PWOM about durables differ from those responsible for NWOM; here again, durables differed from services where PWOM and NWOM were triggered by factors in the same proportions.

\section{References}

Anderson, E.W., Fornell, C. and Rust, R.T. (1997). Customer satisfaction, productivity, and profitability: Differences between goods and services, Marketing Science, 16(2), 129-45.

Bass F.M. (1969). A new product growth model for consumer durables. Management Science 15(5): 215-227.

Bayus B.L. (1985). Word of mouth: The indirect effects of marketing efforts. Journal of Advertising Research, 25(3):31-9.

Day, R.L. and Ash, S.B. (1979). Consumer response to dissatisfaction with durable products Advances in Consumer Research, 6, 438-44.

Dichter, E. (1966). How word-of-mouth advertising works, Harvard Business Review, 44 (6), 147-166.

East, R., Hammond, K. and Lomax, W. (2008). Measuring the impact of positive and negative word of mouth on brand purchase probability, International Journal of Research in Marketing, 25(3), 215-224.

East, R., Hammond, K. and Wright, M. (2007). The relative incidence of positive and negative word of mouth: a multi-category study, International Journal of Research in Marketing, 24(2), 175-184. 
East, R., Uncles, M., Romaniuk, J. and Dall'Olmo Riley, F. (2015). Antecedents of word of mouth about services. Accepted by the International Journal of Market Research.

Ehrenberg, A.S.C. (1988). Repeat Buying: Theory and Applications (2nd ed), London: Charles Griffin \& Co. (first published in 1972 by North Holland)

Feng Z. and Zhang X. (Michael) (2010). Impact of online consumer reviews on sales:The moderating role of product and consumer characteristics, Journal of Marketing, 74(March), 133-148.

Givon, M. and Horsky, D. (1990). Untangling the effects of purchase reinforcement and advertising carryover, Marketing Science, 9(2), 171-187.

Graham J. and Havlena W.J. (2007). Finding the 'Missing Link': Advertising's impact on word of mouth, web searches, and site visits. Journal of Advertising Research, 47(4):42735.

Hu, Y., Lodish, L.M. and Krieger, A.M. (2007) An analysis of real world TV advertising tests: a 15-year update, Journal of Advertising Research, 47(3), 341-353.

Katz E (1957). The two-step flow of communications: An up-to-date report on an hypothesis. Political Opinion Quarterly 21(1): 61-78.

Keller, E. and Fay, B. (2012). The Face-to-Face Book, New York: Free Press.

Keller Fay Agency (2014). http://www.kellerfay.com/category/blog/

Lazarsfeld P.F., Berelson B. and Gaudet H. (1944). The People's Choice: How the Voter Makes up his Mind in a Presidential Campaign. New York: Columbia University Press.

MacKenzie, S.B. and Podsakoff, P.M. (2012). Common method bias in marketing: Causes, mechanisms, and procedural remedies, Journal of Retailing, 88(4), 542-555.

Mangold, W.G., Miller, F, and Brockway, G.R. (1999). Word-of-mouth communication in the service marketplace, Journal of Services Marketing, 13(1), 73-89.

Podsakoff, P.M., MacKenzie, S.B., and Podsakoff, N.P. (2012). Sources of method bias in social science research and recommendations on how to control it, Annual Review of Psychology, 63, 539-569.

Peterson, R.A. and Wilson, W.R. (1992). Measuring customer satisfaction: Fact or artifact, Journal of the Academy of Marketing Science, 20(1), 61-71.

Sweeney, J., Soutar, G. and Mazzarol, T. (2014). Factors enhancing word-of-mouth influence: Positive and negative service-related messages, European Journal of Marketing, 48(1/2), 336-59.

Sundarum, D.S., Mitra, K. and Webster, C. (1998). Word-of-mouth communications, Advances in Consumer Research, 25, 527-31.

Tarde G. (1890). Les Lois de l'Imitation. (Réimpression, Paris: Kimé Éditeur, 1993).Translated as The Laws of Imitation (1902) by E. Parsons, New York: Henry Holt. 